\title{
Embedded systems engineering for products and services design
}

\author{
Tareq Z. Ahram ${ }^{\mathrm{a}^{*}}$, Waldemar Karwowski ${ }^{\mathrm{a}}$, Marcelo M. Soares ${ }^{\mathrm{b}}$ \\ ${ }^{a}$ Institute for Advanced Systems Engineering, , University of Central Florida, Orlando, FL 32816, USA \\ ${ }^{\mathrm{b}}$ Department of Design, Federal University of Pernambuco, CAC, Cidade Universitaria - 50.670-420 Recife, PE, \\ Brazil
}

\begin{abstract}
Systems engineering (SE) professionals strive to develop new techniques to enhance the value of contributions to multidisciplinary smart product design teams. Products and services designers challenge themselves to search beyond the traditional design concept of addressing the physical, social, and cognitive factors. This paper covers the application of embedded user-centered systems engineering design practices into work processes based on the ISO 13407 framework [20] to support smart systems and services design and development. As practitioners collaborate to investigate alternative smart product designs, they concentrate on creating valuable products which will enhance positive interaction. This paper capitalizes on the need to follow a user-centered SE approach to smart products design [4, 22]. Products and systems intelligence should embrace a positive approach to user-centered design while improving our understanding of usable value-adding, experience and extending our knowledge of what inspires others to design enjoyable services and products.
\end{abstract}

Keywords: Smart Products; service systems, Systems Engineering; Embedded Systems

\section{Introduction}

The introduction of user-centered systems engineering methodology and design principles to design smarter products has been inspired by the theory of smart environments developed in Germany $[8,13,34)$. Intelligent and integrated systems has affected industrial and economical growth in many nations. These developments have strengthened the need for emphasizing the role of information and knowledge in smart systems. A revolution sparked by Smart Systems with its new information society is taking over what has been known as the industrial society [17]. Smart Systems design considers qualitative attributes between human-human and human-machine interactions. These considerations include workforce integration (i.e., those who design the system and provide the service) and customers or users (i.e., those who receive and use the product or service). Smart Systems design also describes the necessary objects and/or components that constitute intelligent design. During the design process, a designer selects a group of objects and attributes from the design continuum and assigns a value to each attribute that best fits the objectives and constraints specified by the owner [21]. The resulting Smart Systems concept is a qualitative and quantitative description of a system in terms of integrated objects representing functionally effective components.

User-centered Smart Systems (USS) design is characterized by the relationship between knowledge and technology. USS involves the knowledge that is required to deliver the smart product, whether it is invested in the technology of the product or in the service provider $[19,28]$. Knowledge requirements in intelligent systems design and modeling have been categorized into three main categories: knowledgebased, knowledge-embedded, and knowledgeseparated [28]. Research has indicated that a knowledge-based smart system, such as teaching aid systems, depends on customer knowledge to deliver intended functionality. This knowledge may become embedded in a product that makes the service accessible to more people. An example of this is logistics

${ }^{*}$ Corresponding author. E-mail: tahram@ucf.edu 
providers, where the technology of package delivery is tracked by Radio Frequency Identification (RFID) embedded in the package and the system that schedule and route the delivery of packages. It is important to note, however, that the delivery personnel are critical components in both the delivery and pickup stages. Their knowledge is crucial in satisfying customers and providing quality service. The USS approach contributes to systems development processes rather than replaces them. This is achieved by implementing Human Factors \& Ergonomics (HFE) principles along with product design and Usability Engineering (UE) procedures to design user friendly products and analyze users-system interactions. The following key principles of USS have been identified:

- Clear understanding of user and task requirements: Key strengths of USS design are the spontaneous and active involvement of product or service users and the understanding of their task requirements. Involving end users will improve system acceptance and increase commitment to the success of the new product.

- Consistent allocation of functions between users and intelligent system: Allocation of functions are based on full understanding of customer capabilities, limitations, and task demands.

- Iterative smart system design approach: Iterative smart system design solutions include processing responses and feedback from product or system users after their use of proposed design solutions. Design solutions could range from simple paper prototypes to high-fidelity smart systems mockups.

- Multidisciplinary integration design teams: USS design is a multitasking collaborative process that involves multidisciplinary design teams. It is crucial that the smart system design team comprise professionals and experts with suitable skills and interests in the proposed system design. Such a team might include end users, smart product handlers (front-stage smart system designers), software integration managers, usability specialists, software engineers (back-stage smart system designers), interaction designers, user experience architects, and training support professionals.

Consumers of a smart product develop knowledge in order to use the system. In knowledge-separated systems, the smart product may be accessible to customers without needing to interact with another human being in the loop. An example of this is the ticketing kiosks at the airport, which have replaced airline representatives. The knowledge of the airline representa- tive is now fully embedded in the ticketing kiosk and integrated with government and airline up-to-date databases. Now a traveler must only have the knowledge to operate the machine. All these components are incorporated and organized in a scheme originating from a generalized definition of a system $[10,21,30]$

"A system is an organized set of objects which processes inputs into outputs that achieve an organizational purpose and meets the need of customers through the use of human, physical and informatic enablers in a sociological and physical environment".

USS design involves three main components: smart product problem structuring, idea generation, and idea evaluation and selection. This approach helps smart product designers to integrate new connections between various product elements, recognize key processes and elements in the system and recombine them in different ways, identify elements of purpose, and focus on goals. The primary mechanism of customer value creation is divided between customer knowledge, machines and technological knowledge $[4,28]$.

\section{The smart products}

The concept of smartness of consumer products has been investigated by several authors. This section presents a synthesis and summary of the most innovative work that influenced research in this field. Allmendinger and Lombreglia [6] highlighted smartness in a product from a business perspective. They regard "smartness" as the product's capability to predict business errors and faults, thus "removing unpleasant surprises from [the users'] lives." The Ambient Intelligence (AMI) group described a vision where distributed services, mobile computing, or embedded devices in almost any type of environment (e.g., homes, offices, cars), are integrated seamlessly with one another using information and intelligence to enhance user experiences [1,7,35]. Rapid technological advancements and agile manufacturing created what is called today smart environments. Smart products have to be considered in the context of their environment. Ahram et. al [3] and Das and Cook [11] define a smart environment as the one that is able to acquire and apply knowledge about an environment and adapt to its inhabitants in order to improve their experience in that environment. A key issue is the 
knowledge aspect as further noted by Mühlhäuser [29] references to smart product characteristics that are attributed to future smart environments: i.e., "integrated interwoven sensors and computational systems seamlessly embedded in everyday systems and tools of our lives, connected through a continuous network." In this respect, smarter products can be viewed as those products that facilitate daily tasks and augment everyday objects. In 2007, AMI identified two motivating goals for building smart products [33]:

1) Increased need for simplicity in using everyday products as their functionalities become ever more complex. Simplicity is desirable during the entire life-cycle of the product to support manufacturing, repair and use.

2) Increased number, sophistication, and diversity of product components (for example, in the aerospace industry), as well as the tendency of the suppliers and manufacturers to become increasingly independent of each other which requires a considerable level of openness on the product side.

Mühlhäuser [29] observed that these product characteristics can now be developed due to recent advances in information technology as well as ubiquitous computing that provides a real world awareness in these systems through the use of sensors, smart labels, and wearable, embedded computers. According to Mühlhäuser [29], product simplicity can be achieved with improved product to user interaction (p2u). Furthermore, openness of a product requires an optimal product to product interaction $(\mathrm{p} 2 \mathrm{p})$.

Knowledge intensive techniques enable better product to product interaction through selforganization within a product or a group of products. Indeed, recent research on semantic web service description, discovery, and composition may enable self-organization within a group of products, and therefore, reduce the need for top-down constructed smart environments [9]. Smart products also require some level of internal organization by making use of planning and diagnosis algorithms as stated by Mühlhäuser [29]:

"A Smart Product is an entity (tangible object, software, or service) designed and made for self-organized embedding into different (smart) environments in the course of its lifecycle, providing improved simplicity and openness through improved $p 2 u$ and $p 2 p$ interaction by means of context-awareness, se- mantic self- description, proactive behavior, multimodal natural interfaces, AI planning, and machine learning."

The Smart Products Consortium (SPC) has adopted and modified the definition given in Mühlhäuser [29]. The new definition provides an industry-applicable, life-cycle development methodology with tools and platforms to support the construction of smart products and emphasis on tangible objects as smart products (i.e., physical products). The SPC defined smart products as follows Sabou et al. [33]:

"A smart product is an autonomous object which is designed for self-organized embedding into different environments in the course of its life-cycle and which allows for a natural product-to-human interaction. Smart products are able to proactively approach the user by using sensing, input, and output capabilities of the environment thus being self-, situational-, and context-aware. The related knowledge and functionality can be shared by and distributed among multiple smart products and emerges over time."

Major characteristics of smart products are illustrated by comparing their essential features. For example, Maass and Varshney [24] define six major characteristics (see Table 1) for smart products. These characteristics highlight the following major functions:

- Context-awareness: the ability to sense context

- Proactivity: the ability to make use of this context and other information in order to proactively approach users and peers

- Self-organization - the ability to form and join networks with other products. 
Table 1: Smart Products Characteristics (Modified from Maass and Varshney [24])

\begin{tabular}{l|l}
\hline \multicolumn{1}{c|}{ Characteristic } & \multicolumn{1}{|c}{ Description } \\
\hline Personalization & $\begin{array}{l}\text { Customization of products ac- } \\
\text { cording to buyer's and consum- } \\
\text { er's needs. } \\
\text { Consideration of business and } \\
\text { legal constraints. } \\
\text { awareness }\end{array}$ \\
Situatedness & $\begin{array}{l}\text { Recognition of situational and } \\
\text { community contexts. } \\
\text { Change product behavior ac- } \\
\text { cording to buyer's and consum- } \\
\text { er's responses to tasks. }\end{array}$ \\
Network ability & $\begin{array}{l}\text { Ability to communicate, inte- } \\
\text { grate and bundle with other } \\
\text { products. } \\
\text { Anticipation of user's plans and } \\
\text { intentions. }\end{array}$ \\
\hline
\end{tabular}

Mühlhäuser [29] and SPC emphasize the fact that smart products should support their entire life-cycle. In addition, special care should be devoted to offering multimodal interaction with the potential users, in order to increase the simplicity characteristics of the products.

\section{Systems engineering approach for design and modeling of smart products}

Systems engineering (SE) concepts and principles are an integral part of the contemporary engineered world $[4,18]$. Such concepts are also used to create smarter consumer products, produce food, protect human health, enable travel over great distances, and allow for instant and ubiquitous communication. These principles are also used to build houses, design workplaces, and develop an infrastructure upon which society relies. The SE principles are used to make services and products cheaper, more functional, and get them to the market faster. Systems engineers apply and integrate concepts and rules derived from math and science to create and apply such

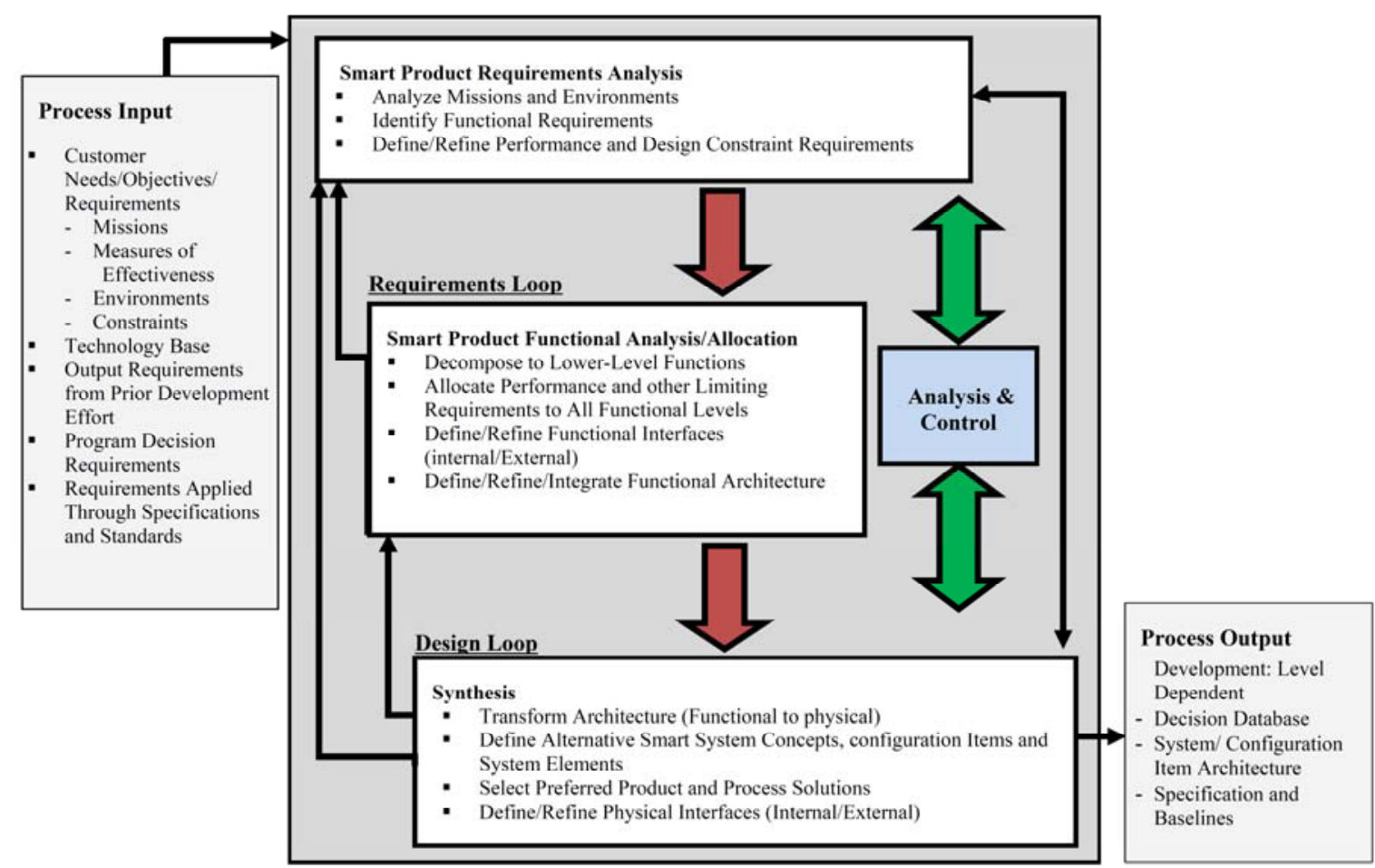

Figure 1: Framework for Smart Products SE Process (Modified from original by DAU Guidebook [12]) 
principles [4,3]. For example, The energy used to heat, cool, and light residential or industrial dwellings is typically generated hundreds of miles away from where it is used and needs to be transferred over long distances. Systems engineering concepts supports building smart grid infrastructure and efficient energy distribution networks.

The contemporary SE process is an iterative, hierarchical, top down decomposition of system requirements (Hitchins 2007). The hierarchical decomposition includes Functional Analysis, Allocation, and Synthesis. The iterative process begins with a system-level decomposition and then proceeds through the functional subsystem level all the way to the assembly and program level (see Figure 1). Modeling SE Process Activity is performed using Systems Modeling Language (SysML).

SysML is a general purpose visual modeling language for specifying, analyzing, designing, and verifying complex systems which may include hardware, software, information, personnel, procedures and facilities (OMG SysML: http://www.omgsysml.org). SysML provides visual semantic representations for modeling system requirements, behavior, structure, and parametrics, which is used to integrate with other engineering analysis models [15].

\section{The benefits of User-centered Systems engineering design methods and strategies}

User-centered design methods and strategies are concerned with incorporating the user's perspective into the systems development process to achieve usable systems and smarter products or improve existing ones. This section adopts the framework of ISO 13407 [20] where each step in the user-centered design cycle is evaluated with supporting usability methods. Product usability is now widely recognized as one of the critical success factors of an interactive product development process [14, 20, 31, 32]. Unfortunately, poorly designed, unusable systems exist, which end users find difficult to use. Poor system provisions are costly for an organization and negatively affect the reputation of the smart product vendor. Dissatisfied customers may go so far as to find and choose a substitute vendor with a better system. User-centered design processes and methods help design better systems and increase quality to meet customer expectations. The benefits of following user-centered design principles in systems have been summarized by Maguire [25-26]
- Reduced training and support: User-centered design and usability principles help reduce smart product provider training time and the need for user support. This is of special importance to novel systems since newly introduced smart systems most often require dedicated training and support.

- Reduced errors: Poorly designed smart systems significantly increase human error due to inconsistencies, ambiguities, or other interface design faults.

- Increased productivity: A smart system employing user-centered design and usability principles will enable users to concentrate on the task rather than the interface in order to operate effectively.

- Improved user population acceptance: Most users would be more likely to trust a smart system that provides well-presented information which is easily accessed, increasing end-user acceptance and enhancing customer satisfaction.

- Enhanced reputation: A well-designed system will enhance the vendor's reputation in the marketplace and guarantee profitability and customer support for future products and services.

\section{The User-centered Smart System development cycle}

The ISO 13407 human-centered design framework is considered the cornerstone for incorporating different design techniques of which all can be merged to support a user-centered design process. According to the ISO 13407 standard [20], appropriate USS processes are composed of five iterative steps which will guarantee the fulfillment of all requirements into the system design process as follows:

- Planning systems design processes

- Smart product context of use

- Requirements specification

- Integration of design solutions

- Smart systems evaluation and assessment

The five iterative user-centered systems design steps are based on the ISO 13407 framework and are depicted in Figure 2. The first step in planning smart system design processes is to communicate smart needs with stakeholders and users to gain agreement on how user-centered design techniques can contribute to the smart system objectives $[23,2]$. In addition, the planning process prioritizes smart product requirements and highlights potential benefits gained 
from including USS activities within the system development process.

\subsection{Smart product context of use}

Smart product context of use defines all aspects of the system's intended usage as well as the user population characteristics (i.e., user profile). Developed systems will be used within a certain set of tasks by users with defined results and goals by performing certain activities. The system will also be used within a known context of physical, environmental, and organizational conditions. Capturing smart product context of use is important for helping to specify user requirements as well as for evaluation and testing. Best practices indicate that effective smart products and systems strongly promote usability, end-user health and safety, and proper understanding of the context of use. Context of use information can be gathered using established structured methods for eliciting detailed information. This information will help facilitate usability evaluation activities, user requirements specification, and system evaluation. Smart product context of use information provides details about the user's profile and characteristics, as well as, task and environment of smart product usage. Following is a description of each step in the usercentered design cycle.

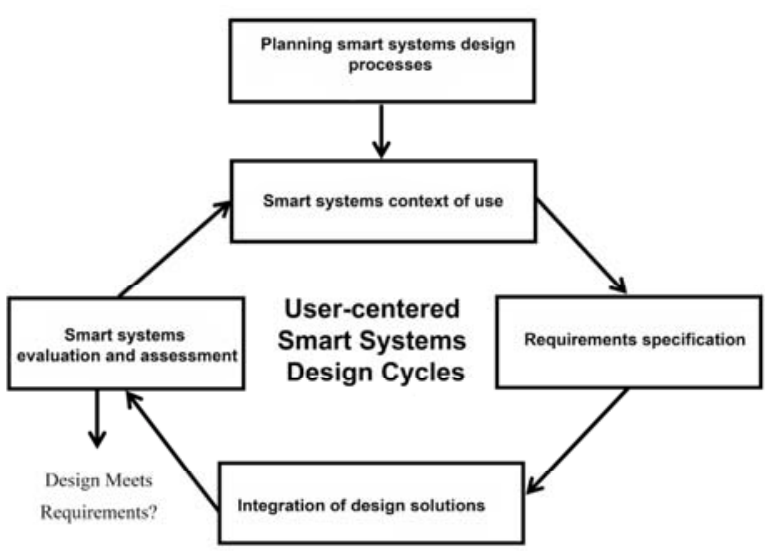

Fig. 2: User-centered smart system (USS) design cycle. (Modified from original ISO 13407 framework [20]).

\subsection{Requirements specification}

Requirements specification is one of the most crucial activities of system design and development. The two most common causes of system failure are insufficient effort to identify user requirements and lack of end-user involvement in the design process. ISO 13407 design framework [20] provides guidance on specifying end-user requirements and objectives. The framework states that the following elements should be covered in the specification:

- Identification of users and other personnel in the smart product design (e.g. customers, employees, associates, designers, and support)

- Clear statement of the smart product's design and integration goals

- Inclusion of appropriate priorities for the different requirements

- Establishment of measurable benchmarks for which design can be tested

- Acceptance of design requirements by end-users and stakeholders

- Acknowledgment of mandatory or legislative requirements

- Documentation of the requirements and manage changing requirements as the system develops.

\subsection{Integration of design solutions}

Design solutions start with innovative and creative ideas through the iterative development process. Low-fidelity prototypes are necessary inclusions to the design lifecycle. Design prototypes can be produced by human factors professionals and the design team. Major problems can be identified before system development proceeds too far along because it is always cheaper and easier to make changes sooner rather than later in the systems design life cycle (SDLC). Systems design methods provide techniques for generating ideas and new system designs through storyboarding, brainstorming, parallel design, and Wizard-of-Oz techniques [23]. The process of iterative design and development requires proper documentation of changes to maintain effective management.

\subsection{Smart systems evaluation and assessment}

Smart products should be evaluated during all design and development stages. Evaluation helps confirm that the intended objectives have been met and provide further information for refining the de- 
sign. System evaluation starts with low-fidelity prototypes, followed by more sophisticated high-fidelity prototypes. Evaluation and assessment helps improve the smart product as part of the iterative development process and assures the smart product can be used successfully by intended users. Smart product evaluation and assessment can highlight problems by either user or expert-based methods. Expert-based methods can help find weaknesses that may not be revealed by a small number of users. User-based testing is required to find out whether intended users can interact with the product successfully. When running user testing, the emphasis may be on identifying problems and addressing them in the design process.

Innovation in USS is defined as putting creative ideas into actions while creativity in USS is usually expressed as the generation of ideas towards improving products; creativity and innovation are totally different concepts in smart systems design and modeling [16,21] From a user-centered design perspective, creativity involves divergent thinking from the ordinary design perspective. Whereas, innovation involves convergent thinking mixed with creative ideas in systems. McAdam and McClelland [27] illustrated the vital importance of innovation in engineering, especially, smart systems by indicating that idea generation is a key component of creativity.

\section{Conclusions}

System engineering (SE) professionals strive to develop new techniques to enhance the value of contributions to multidisciplinary smart product design teams. SE designers challenge themselves to search beyond the traditional design concept of addressing the physical, social, and cognitive factors. This chapter covers the application of user-centered systems engineering design practices based on the ISO 13407 framework to support smart systems design and development. As practitioners collaborate to investigate smart product designs, they concentrate on creating valuable products which will enhance positive interaction.

In conclusion, this paper stresses the need to follow a user-centered SE approach to smart products design. Products and systems intelligence should embrace a positive approach to user-centered design while improving our understanding of usable valueadding, experience and extending our knowledge of what inspires others to design enjoyable services and products.

\section{References}

[1] J. Ahola, 2001. Ambient Intelligence. ERICM News 47.

[2] T. Z. Ahram, W. Karwowski, 2009. Measuring Human Systems Integration Return on Investment. The International Council on Systems Engineering - INCOSE Spring 09 Conference: Virginia Modeling, Analysis and Simulation Center (VMASC), Suffolk, VA. USA.

[3] T. Z. Ahram, W. Karwowski, B. Amaba, P. Obeid, 2009. Human Systems Integration: Development Based on SysML and the Rational Systems Platform, Proceedings of the 2009 Industrial Engineering Research Conference, Miami, FL. USA.

[4] T. Z. Ahram, W. Karwowski, and M. Soares (2011) "Smarter Products User-Centered Systems Engineering" In: Waldemar Karwowski, Marcelo Soares and Neville Stanton (eds.). Handbook of Human Factors and Ergonomics in Consumer Product Design. Methods and Techniques. Taylor \& Francis. Boca Raton, FL

[5] T. Z. Ahram, W. Karwowski, B. Amaba, 2010. Usercentered Systems Engineering \& Knowledge Management Framework for Design \& Modeling of Future Smart Cities. 54th Annual Meeting of the Human Factors and Ergonomics Society (HFES 2010). San Francisco, California, USA.

[6] G. Allmendinger, , and R. Lombreglia, 2005. Four Strategies for the Age of Smart Services. Harvard Business Review 83(10):131-145.

[7] E. Arts, and B. de Ruyter 2009. New research perspectives on ambient intelligence. Journal of Ambient Intelligence and Smart Environments 1:5-14.

[8] H. Bullinger, and A.-W Scheer, 2003. Introduction. In: H.-J. Bullinger, and A.-W. Scheer, eds. Service Engineering: Entwicklung und Gestaltung Innovativer Dienstleistungen. Springer, Berlin.

[9] S. Chandrasekharan, 2004. The Semantic Web: Knowledge representation and affordance. In: Cognition and Technology: Co-existence, Convergence, and Coevolution, ed. B. Gorayska and J.L. Mey, J.L. Amsterdam/Philadelphia: Benjamins, 153-174

[10] P. B. Checkland, 1981. Systems Thinking Systems Practice. New York: Wiley.

[11] S. Das, D.Cook, 2006. Designing Smart Environments: A Paradigm Based on Learning and Prediction. In: Shorey, R., Ananda, A., Chan, M.C., Ooi, W.T. (eds.) Mobile, Wireless, and Sensor Networks: Technology, Applications, and Future Directions, 337-358. Wiley, Chichester

[12] Defense Acquisition University (DAU) Guidebook 2004. Chapter 4: Systems Engineering.

[13] De Jong, J.P.J., and Vermeulen, P.A.M. 2003. Management Decision 41 (9): 844-858.

[14] C. Fowler, 1991. Usability evaluation-usability in the product lifecycle. Usability Now! Newsletter, Issue 3, Spring, 6-7. HUSAT Research Institute. The Elms, Elms Grove, Loughborough, Leicestershire, UK. 
[15] S. Friedenthal, A. Moore, R. Steiner, 2008. A Practical Guide to SysML: The Systems Modeling Language, Morgan Kaufmann; Elsevier Science.

[16] D. Gurteen, 1998. Knowledge, creativity and innovation. Journal of Knowledge Management 2: 5-13.

[17] Hauknes, J. 1996. Innovation in the Service Economy, STEP group Storgt. $1 \mathrm{~N}-0155$ Oslo, ISSN 0804-8185.

[18] Hitchins, D. K. 2007. Systems Engineering: A 21st Century Systems Methodology. Chichester, UK: John Wiley \& Sons.

[19] H. E. Hulshoff, F.M.J. Westhof, J. J. Kirchhoff, B. A. Kirchhoff, , and S. T. Walsh, 1998. New services: Strategic exploratory survey of a dynamic phenomenon. EIM Small Business Research and Consultancy, Zoetermeer, NL.

[20] ISO 13407: Human-centered Design Processes for Interactive Systems. International Standards Organization, Geneva, 1999. Also available from the British Standards Institute, London.

[21] Kaner, M., and Karni, R. 2007. Engineering design of a service system: An empirical study. Information Knowledge Systems Management 6: 235-263, IOS Press.

[22] W. Karwowski, T. Z. Ahram, 2009. Interactive Management of Human Factors Knowledge For Human Systems Integration Using Systems Modeling Language. Special Issue for Information Systems Management. Journal of Information Systems Management. Taylor and Francis.

[23] W. Karwowski, G. Salvendy, T. Z. Ahram, 2009 Customer-centered Design of Service Organizations. In: Introduction to Service Engineering, ed. G. Salvendy, W. Karwowski, Chapter 9. John Wiley \& Sons, NJ (ISBN-10: 0470382414).

[24] W. Maass and U. Varshney 2008. Preface to the Focus Theme Section: 'Smart Products'. Electronic Markets 18(3): 211-215

[25] M. C. Maguire, 2001a. Context of use within usability activities. International Journal of Human-Computer Studies 55: 453-483, doi:10.1006/ijhc.2001.0486.

[26] M. C. Maguire, 2001b. TAQ and SAQ: Pre and post test questionnaires for assessing user acceptance. HUSAT Memo HM1148, June 2001. HUSAT Research Institute, The Elms, Elms Grove, Loughborough, Leicestershire LE11 1RG, UK.

[27] R. McAdam, , and J. McClelland, 2002. Individual and team-based idea generation within innovation management: Organizational and research agendas. European Journal of Innovation Management 5 (2): 86-97.

[28] C. M. McDermott, H. Kang, and S. Walsh, 2001. A framework for technology management in services. IEEE Transactions in Engineering Management 48 (3): 333-341.

[29] M. Mühlhäuser, 2008. Smart Products: An Introduction. In Constructing Ambient Intelligence - AmI 2007 Workshop, pages $154-164$.

[30] G. Nadler, and S. Hibino, 1998. The Seven Principles of Creative Problem Solving. Prima, Rocklin, CA.
[31] J. Nielsen, 1994a. Special Issue: Usability laboratories. Behavior and Information Technology 13, 3-197.

[32] J. Nielsen, 1994b. Usability Engineering. San Francisco: Morgan-Kauffman.

[33] M. Sabou, J. Kantorovitch, , A. Nikolov, A.Tokmakoff, X. Zhou, , and E. Motta, , 2009. Position Paper on Realizing Smart Products: Challenges for Semantic Web Technologies, Report by Knowledge Media Institute: http://people.kmi.open.ac.uk/marta/papers/ssn2009.pdf

[34] A. Scheer, and D. Spath, eds. 2004. Computer Aided Service Engineering: Informationssysteme in der Dienstleistungsentwicklung. Berlin: Springer.

[35] M. Weiser 1991. The computer of the 21st century. Scientific American 265(3): 66-75. 